\title{
ENRAIZAMENTO DE ESTACAS DO HÍBRIDO SOMÁTICO LARANJA ‘CAIPIRA’ + LIMÃO 'VOLKAMERIANO’ E DE SEUS GENITORES ${ }^{1}$
}

\author{
MEIRE MENEZES BASSAN², FRANCISCO DE ASSIS ALVES MOURÃO FILHO, \\ BEATRIZ MADALENAJANUZZI MENDES ${ }^{4}$
}

RESUMO-Objetivou-se neste trabalho comparar o enraizamento de estacas do híbrido somático laranja 'Caipira' (C. sinensis L. Osbeck) + limão ‘Volkameriano' (C. volkameriana V. Tennore et Pasquale) com aquelas dos seus genitores tratadas com ácido indolbutírico (AIB) (0; 500; 1.000 e $\left.2.000 \mathrm{mg} \mathrm{L}^{-1}\right)$. As estacas de laranja 'Caipira' e limão 'Volkameriano' foram retiradas de plantas obtidas a partir de sementes, e as do híbrido somático, de plantas enxertadas recém-podadas. O delineamento experimental utilizado foi um fatorial 3 x 4 (genótipos x concentrações de AIB) inteiramente casualizado, com quatro repetições de 10 estacas por repetição, totalizando 480 estacas. As estacas foram cultivadas em bandejas de poliestireno expandido, contendo substrato comercial, em estufa com sistema de nebulização intermitente, por 90 dias. A produção de plantas enraizadas foi altamente eficiente para os três genótipos avaliados, considerando-se a maioria das variáveis relacionadas ao enraizamento e vigor das estacas, independentemente do uso de AIB. Estacas de limão ‘Volkameriano’ apresentaram médias de comprimento e massa seca das raízes superiores às dos demais genótipos. Para todos os genótipos, as porcentagens de estacas vivas e enraizadas foram elevadas (acima de 90\%), indicando o alto potencial deste germoplasma para ser utilizado na produção de mudas e porta-enxertos por estaquia.

Termos para Indexação: biotecnologia, Citrus, estaquia, porta-enxerto, rizogênese.

\section{ROOTING OF ‘CAIPIRA'SWEET ORANGE + 'VOLKAMER’LEMON SOMATIC HYBRID CUTTINGS AND THEIR PROGENITORS}

\begin{abstract}
This work aimed to compare the rooting capacity of cuttings of the somatic hybrid 'Caipira' sweet orange (C. sinensis L. Osbeck) + 'Volkamer' lemon (C. volkameriana V. Tennore et Pasquale) with those of their progenitors treated with indol butyric acid (IBA) (0, 500, 1000 and $\left.2000 \mathrm{mg} \mathrm{L}^{-1}\right)$. Cuttings of 'Caipira' sweet orange and 'Volkamer' lemon were collected from seed derived plants, whereas those of the somatic hybrid were obtained from recently pruned grafted plants. The experimental design was a completely randomized block $3 \times 4$ factorial (genotypes x IBA concentrations), with four replications (10 cuttings per replication) in a total of 480 cuttings. Cuttings were cultivated in expanded polystyrene trays filled with commercial potting mix, inside an intermittent mist chamber, for 90 days. The production of the rooted plants was highly efficient for the three genotypes evaluated, considering most of the variables related with rooting and cutting vigor, regardless the use of IBA. 'Volkamer' lemon cuttings had higher root length and root dry mass than the other genotypes. However, percentage of live cuttings, rooted cuttings and sprouted cuttings were high (above 90\%) for all evaluated genotypes, indicating the great potential of this material to be used in nursery tree multiplication through cuttings.
\end{abstract}

Index terms: biotechnology, Citrus, cutting propagation, root induction, rootstock

\footnotetext{
${ }^{1}$ (Trabalho 143-08). Recebido em: 09-06-2008. Aceito para publicação em: 13-01-2009.

${ }^{2}$ Aluna de graduação em Engenharia Agronômica. ESALQ/USP, Piracicaba-SP. Bolsista CNPq. Email: mmbassan@esalq.usp.br ${ }^{3}$ Eng. Agr., Dr., Professor Associado. Departamento de Produção de Vegetal, ESALQ/USP, Caixa Postal 9. 13418-900, Piracicaba-SP. Bolsista CNPq. Autor Correspondente. Email: famourao@esalq.usp.br

${ }^{4}$ Eng. Agr., Dra., Professora Associada. Centro de Energia Nuclear na Agricultura, CENA/USP, Piracicaba-SP. Bolsista CNPq. Email: mendes@cena.usp.br
} 
O porta-enxerto é de fundamental importância na formação da muda cítrica, pois interfere no desenvolvimento e vigor da copa, precocidade de produção, quantidade e qualidade da produção, época de maturação dos frutos, resistência a pragas e doenças, bem como na capacidade de adaptação da planta às condições edafoclimáticas desfavoráveis, preservando as características fundamentais das copas desejadas (Castle \& Youtsey, 1977).

Por outro lado, recentes programas de melhoramento de porta-enxertos têm sido desenvolvidos com a integração de diversas ferramentas biotecnológicas, a exemplo da produção de híbridos somáticos por fusão de protoplastos, como é o caso dos citros (Grosser et al., 1998). Essa técnica apresenta a vantagem de combinar o genoma integral dos dois genitores envolvidos, permitindo a utilização dos híbridos diretamente como portaenxertos. Além disso, permite a produção de híbridos somáticos entre Citrus e gêneros relacionados, sexualmente incompatíveis (Costa et al., 2003).

O enraizamento de estacas é um dos métodos utilizados para a obtenção de porta-enxertos, pois mantém as características genéticas da planta-matriz e pode incrementar o número de plantas rapidamente. Nesse método, as auxinas são fitorreguladores que podem desempenhar importante papel por estarem diretamente relacionados à indução e desenvolvimento de raízes. O ácido indolbutírico (AIB) tem sido frequentemente utilizado, inclusive naqueles estudos relacionados a citros (Santos et al., 1988), e ainda representa a auxina sintética mais empregada atualmente em trabalhos desse gênero.

Trabalhos científicos comprovaram a eficiência da propagação de citros por estaquia, em especial da lima-ácida 'Tahiti' (Citrus latifolia Tanaka), com alta porcentagem de enraizamento (Prati et al., 1999). Em experimentos que envolvem a produção de híbridos somáticos, após a confirmação da hibridação, a estaquia é a técnica mais viável para a rápida propagação, visando à avaliação inicial de matrizes selecionadas (Pio et al., 2006).

O objetivo deste trabalho foi comparar a capacidade de enraizamento de estacas tratadas com diferentes concentrações de AIB de um híbrido somático com aquela dos seus genitores.

O experimento foi conduzido em área experimental do Departamento de Produção Vegetal da Escola Superior de Agricultura “Luiz de Queiroz”, Universidade de São Paulo (ESALQ/USP), em Piracicaba-SP. O híbrido somático avaliado foi laranja 'Caipira' (Citrus sinensis L. Osbeck) + limão 'Volkameriano' (C. volkameriana V. Tennore et
Pasquale), o qual foi produzido, visando a combinar a tolerância da laranja ‘Caipira’ ao declínio dos citros com a rusticidade, precocidade de produção e resistência ao estresse hídrico do limão 'Volkameriano' (Mendes et al., 2001).

Estacas semilenhosas de laranja 'Caipira' e de limão 'Volkameriano’ foram coletadas de plantas obtidas de sementes com aproximadamente 10 meses de idade, cultivadas em sacolas plásticas, enquanto as do híbrido somático (laranja 'Caipira' + limão 'Volkameriano’) foram colhidas de plantas enxertadas recém-podadas, com aproximadamente quatro anos de idade. Todas as estacas foram padronizadas com $15 \mathrm{~cm}$ de comprimento e dois pares de folhas. Após imersão em solução de AIB (0; 500; 1.000 e 2.000 mg $\mathrm{L}^{-1}$ ), por 5 minutos, as estacas foram acondicionadas em bandejas de poliestireno expandido (72 células), colocando-se uma única estaca por célula, contendo substrato comercial Plantmax Citrus ${ }^{\mathrm{TM}}$. As estacas permaneceram em estufa com sistema de nebulização intermitente $\left[(25 \pm 5){ }^{\circ} \mathrm{C}, 72 \%\right.$ de umidade, nebulização por 20 segundos a intervalos de 10 minutos] por 90 dias (janeiro a março de 2007).

Os dados biométricos avaliados foram porcentagem de estacas vivas, porcentagem de estacas enraizadas, porcentagem de estacas brotadas, número de raízes e número de brotações por estaca, comprimento das raízes e das brotações, e massa seca das raízes. O delineamento experimental foi em esquema fatorial $3 \times 4$ (genótipos $\mathrm{x}$ concentrações de AIB) inteiramente casualizado, com quatro repetições (10 estacas por repetição), totalizando 480 estacas. Os dados foram analisados com o auxílio do programa Estat. Variáveis expressas em porcentagem sofreram transformação do tipo arc seno $\{\sqrt[V]{ }[(\mathrm{x}+\boldsymbol{\alpha}) / 100] \cdot\}$

Os dados coletados indicaram que a produção de plantas enraizadas foi altamente eficiente para os três genótipos avaliados, considerando-se todas as variáveis relacionadas ao enraizamento e vigor das estacas, pois as porcentagens de estacas vivas e enraizadas foram acima de 90\% (Tabela 1). Embora os valores encontrados sejam elevados para todos os genótipos, plantas de limão 'Volkameriano’ e do híbrido somático apresentaram desempenho superior ao das plantas de laranja 'Caipira' no referente à porcentagem de estacas brotadas. Trabalhos anteriores confirmam que estacas de laranja-doce e tangerina apresentam menor capacidade de enraizamento quando comparadas com estacas de lima- ácida 'Tahiti' e de limões (Citrus limon Burmann) (Prati et al., 1999; Reuther et al., 1973). 
A aplicação de AIB não afetou as variáveis avaliadas (Tabelas 1 e 2). Esses resultados também foram encontrados por Pratti et al. (1999) e Villas Boas et al. (1988) em lima-ácida 'Tahiti' e em outras espécies de citros, respectivamente. Discordando desses resultados, aumentos significativos no número, comprimento e diâmetro de raízes com o uso de fitorreguladores vegetais [ácido naftalenoacético (ANA) (1.000 e $3.000 \mathrm{mg} \mathrm{L}^{-1}$ ); AIB (1.000 e $3.000 \mathrm{mg} \mathrm{L}^{-1}$ ) e uma formulação comercial contendo ANA (2.000 $\mathrm{mg} \mathrm{L}^{-1}$ ) e IBA (1.000 $\left.\mathrm{mg} \mathrm{L}^{-1}\right)$ ] foram constatados tanto em variedades diploides citrumelo 'Swingle' (Citrus paradisi x Poncirus trifoliata), 'Flying Dragon' (Poncirus trifoliata var. monstrosa), tangerina 'Cleópatra' (Citrus reshni hort. ex Tanaka) como em tetraploides (tangerina 'Cleópatra' + citrumelo 'Swingle' e tangerina 'Cleópatra' + 'Flying Dragon'), confirmando a eficiência dos fitorreguladores na promoção do desenvolvimento de raízes para algumas variedades de citros (Sabbah et al., 1992).
Em relação ao comprimento de brotação, número de raízes e número de brotações por estaca, observou-se que os três genótipos diferiram entre si, sendo a menor média expressa pela laranja 'Caipira', e a maior, pelo limão ‘Volkameriano’ (Tabela 2). No que se refere ao comprimento médio da maior raiz e massa seca do sistema radicular, o limão 'Volkameriano' apresentou resultados superiores ao híbrido somático (laranja 'Caipira' + limão 'Volkameriano’) e à laranja 'Caipira’ (Tabela 2), confirmando seu elevado vigor já constatado por Castle et al. (1977).

O desenvolvimento deste experimento confirmou resultados anteriores (Pio et al., 2006) e permite concluir que o material avaliado tem alto potencial para ser utilizado na produção de mudas e porta-enxertos por estaquia, devido à alta eficiência no enraizamento das estacas, independentemente do uso de fitorreguladores.

TABELA 1 - Estacas vivas, enraizadas e brotadas de laranja 'Caipira’ (C. sinensis L. Osbeck), limão ‘Volkameriano’ (C. volkameriana Pasquale) e do respectivo híbrido somático, após 90 dias de cultivo sob nebulização intermitente. Piracicaba-SP, 2007.

\begin{tabular}{|c|c|c|c|c|c|}
\hline \multirow[t]{2}{*}{ Genótipo } & \multicolumn{5}{|c|}{$\begin{array}{c}\text { Concentração de AIB } \\
\mathrm{mg} \mathrm{L}^{-1}\end{array}$} \\
\hline & 0 & 500 & 1.000 & 2.000 & Média \\
\hline & \multicolumn{5}{|c|}{$\begin{array}{c}\text { Estacas vivas } \\
(\%)\end{array}$} \\
\hline Laranja 'Caipira' & 85,0 & 87,5 & 97,5 & 97,5 & $91,8 \mathrm{~B}$ \\
\hline Limão 'Volkameriano' & 100,0 & 100,0 & 100,0 & 100,0 & $100,0 \mathrm{~A}$ \\
\hline Laranja 'Caipira' + Limão 'Volkameriano' & 97,5 & 92,5 & 100,0 & 100,0 & $97,5 \mathrm{~A}$ \\
\hline \multirow[t]{2}{*}{ Média } & 94,2 & 93,3 & 99,1 & 99,2 & \\
\hline & \multicolumn{5}{|c|}{$\begin{array}{c}\text { Estacas enraizadas } \\
(\%)\end{array}$} \\
\hline Laranja 'Caipira' & 85,0 & 87,5 & 97,5 & 95,5 & $91,2 \mathrm{~B}$ \\
\hline Limão 'Volkameriano' & 100,0 & 100,0 & 100,0 & 92,5 & $98,1 \mathrm{~A}$ \\
\hline Laranja 'Caipira' + Limão 'Volkameriano' & 97,5 & 92,5 & 100,0 & 100,0 & $97,5 \mathrm{AB}$ \\
\hline \multirow[t]{2}{*}{ Média } & 94,2 & 93,3 & 99,2 & 99,2 & \\
\hline & \multicolumn{5}{|c|}{$\begin{array}{c}\text { Estacas brotadas } \\
(\%)\end{array}$} \\
\hline Laranja 'Caipira' & 32,5 & 40,0 & 60,0 & 47,5 & $45,0 \mathrm{~B}$ \\
\hline Limão 'Volkameriano' & 100,0 & 100,0 & 100,0 & 100,0 & $100,0 \mathrm{~A}$ \\
\hline Laranja 'Caipira' + Limão 'Volkameriano' & 95,0 & 92,5 & 100,0 & 95,0 & $95,6 \mathrm{~A}$ \\
\hline Média & 75,8 & 77,5 & 86,7 & 80,8 & \\
\hline
\end{tabular}

Médias seguidas de mesma letra nas colunas não diferem entre si, pelo Teste de Tukey $(P<0,05)$. 
TABELA 2 - Massa seca das raízes, número e comprimento médio de raízes e brotações das estacas de laranja ‘Caipira’ (C. sinensis L. Osbeck), limão ‘Volkameriano’ (C. volkameriana Pasquale) e do respectivo híbrido somático, após 90 dias de cultivo sob nebulização intermitente. PiracicabaSP, 2007.

\begin{tabular}{lccccc}
\hline Genótipo & \multicolumn{4}{c}{$\begin{array}{c}\text { Concentração de AIB } \\
\text { mg L }^{-1}\end{array}$} \\
& 0 & 500 & 1.000 & 2.000 & Média \\
\hline
\end{tabular}

\begin{tabular}{|c|c|c|c|c|c|}
\hline & 0 & 500 & 1.000 & 2.000 & Média \\
\hline & \multicolumn{5}{|c|}{ Massa seca das raízes } \\
\hline Laranja 'Caipira' & 1,6 & 1,9 & 2,3 & 2,7 & $2,1 \mathrm{~B}$ \\
\hline Limão 'Volkameriano' & 6,7 & 6,8 & 6,3 & 5,5 & $6,4 \mathrm{~A}$ \\
\hline Laranja 'Caipira' + Limão 'Volkameriano' & 2,2 & 2,1 & 2,5 & 3,2 & $2,5 \mathrm{~B}$ \\
\hline \multirow[t]{2}{*}{ Média } & 3,5 & 3,6 & 3,7 & 3,8 & \\
\hline & \multicolumn{5}{|c|}{ Número de raízes } \\
\hline Laranja 'Caipira' & 2,0 & 2,2 & 2,9 & 3,5 & $2,7 \mathrm{C}$ \\
\hline Limão 'Volkameriano' & 8,1 & 7,8 & 7,9 & 7,3 & $7,8 \mathrm{~A}$ \\
\hline Laranja 'Caipira' + Limão 'Volkameriano' & 4,3 & 3,8 & 4,1 & 4,7 & $4,2 \mathrm{~B}$ \\
\hline \multirow[t]{2}{*}{ Média } & 4,8 & 4,6 & 5,1 & 5,2 & \\
\hline & \multicolumn{5}{|c|}{ Número de brotações } \\
\hline Laranja 'Caipira' & 0,5 & 0,7 & 1,0 & 0,7 & $0,7 \mathrm{C}$ \\
\hline Limão 'Volkameriano' & 3,7 & 3,7 & 3,6 & 4,1 & $3,8 \mathrm{~A}$ \\
\hline Laranja 'Caipira' + Limão 'Volkameriano' & 2,6 & 2,5 & 2,7 & 2,4 & $2,5 \mathrm{~B}$ \\
\hline \multirow[t]{2}{*}{ Média } & 2,3 & 2,3 & 2,5 & 2,5 & \\
\hline & \multicolumn{5}{|c|}{$\begin{array}{l}\text { Comprimento das raízes } \\
\qquad(\mathrm{cm})\end{array}$} \\
\hline Laranja 'Caipira' & 8,0 & 7,8 & 8,9 & 9,3 & $8,5 \mathrm{~B}$ \\
\hline Limão 'Volkameriano' & 10,7 & 12,1 & 13,9 & 7,6 & $11,1 \mathrm{~A}$ \\
\hline Laranja 'Caipira' + Limão 'Volkameriano' & 9,0 & 7,8 & 8,8 & 9,1 & $8,7 \mathrm{~B}$ \\
\hline \multirow[t]{2}{*}{ Média } & 9,2 & 9,3 & 10,5 & 8,7 & \\
\hline & \multicolumn{5}{|c|}{$\begin{array}{l}\text { Comprimento das brotações } \\
(\mathrm{cm})\end{array}$} \\
\hline Laranja 'Caipira' & 2,5 & 3,3 & 6,6 & 3,7 & $4,0 \mathrm{C}$ \\
\hline Limão 'Volkameriano' & 13,9 & 13,3 & 13,9 & 11,6 & $13,1 \mathrm{~A}$ \\
\hline Laranja 'Caipira' + Limão 'Volkameri ano' & 9,7 & 8,3 & 9,4 & 9,2 & $9,2 \mathrm{~B}$ \\
\hline Média & 8,7 & 8,3 & 9,9 & 8,2 & \\
\hline
\end{tabular}

Médias seguidas de mesma letra nas colunas não diferem entre si, pelo Teste de Tukey $(P<0,05)$. 


\section{AGRADECIMENTOS}

Ao Eng. Agr. Amancio José de Souza, pelas sugestões ao trabalho; ao Conselho de Desenvolvimento Científico e Tecnológico (CNPq), pela bolsa de iniciação científica (PIBIC) à primeira autora e pela bolsa de produtividade em pesquisa ao segundo e terceiro autores; ao Fundo de Defesa da Citricultura (Fundecitrus), por apoio financeiro.

\section{REFERENCIAS}

CASTLE, W.S.; YOUTSEY, C.O. Root system characteristics of citrus nursery trees. Proceedings of the Florida State Horticultural Society, Orlando, v.90, p.39-44, 1977.

COSTA, M.A.P.C.; MENDES, B.M.J.; MOURÃO FILHO, F.A.A. Somatic hybridisation for improvement of citrus rootstock: production of five new combinations with potential for improved disease resistance. Australian Journal of Experimental Agriculture, Collingwood, v.43, n.9, p.1151-1156, 2003.

GROSSER, J.W.; GMITTER JUNIOR, F.G.; CASTLE, W.S.; CHANDLER, J.L. Somatic hybridization: a new approach to citrus rootstock improvement. Fruits, Paris, v.53, n.5, p.331-334, 1998.

MENDES, B.J.M.; MOURÃO FILHO, F.A.A.; FARIAS, P.C.M.; BENEDITO, V.A. Citrus somatic hybridization with potential for improved blight and CTV resistance. In vitro Cellular \& Developmental Biology - Plant, Columbia, v.37, n.4, p.256- 261, 2001.
PIO, R.; MOURÃO FILHO, F.A.A.; MENDES, F.A.A.; ENTELMANN, F.A.; ALVES, A.S.R. Propagation of citrus somatic hybrids with potential for utilization as rootstocks. Fruits, Paris, v.61, p.1-7, 2006.

PRATI, P.; MOURÃO FILHO, F.A.A.; SANTOS DIAS, C.T.; SCARPARE FILHO, J.A. Estaquia semilenhosa: um método rápido e alternativo para a produção de mudas de lima- ácida 'Tahiti'. Scientia Agricola, Piracicaba, v.56, n.1, p.185-190, 1999.

REUTHER, W. et al. The citrus industry. Berkeley: University of California Press, 1973. p.32-5.

SABBAH, S.M.; GROSSER, J.W.; CHANDLER, J.L.; LOUZADA, E.S. The effect of growth regulators on the rooting of stem cultures of Citrus, related genera and intergeneric somatic hybrids. Proceedings of the Florida State Horticultural Society, Orlando, v.104, p.188-191, 1992.

SANTOS, R.F.; VILLAS BOAS, R.M.F.; SALIBE, A.A. Estudos sobre enraizamento de estacas de citros com aplicação de agentes de efeito hormonal. In: CONGRESSO BRASILEIRO DE FRUTICULTURA, 9., 1987, Campinas. Anais... Campinas: Sociedade Brasileira de Fruticultura, 1988. v.2, p.387-393.

VILLAS BOAS, R.M.F.; SANTOS, R.F.; SALIBE, A.A. Enraizamento de diferentes espécies de citros. In: CONGRESSO BRASILEIRO DE FRUTICULTURA, 9., 1987, Campinas. Anais... Campinas: Sociedade Brasileira de Fruticultura, 1988. p.367-373. 